\title{
Failure of Device to Self-Test
}

National Cancer Institute

\section{Source}

National Cancer Institute. Failure of Device to Self-Test. NCI Thesaurus. Code C62989.

Problem associated with the device failing to perform an internal self-diagnostic process to ensure normal operation during or prior to use. 